Linguagem em (Dis)curso - LemD, v. 9, n. 1, p. 131-155, jan./abr. 2009

\title{
A TATUAGEM COMO GÊNERO: UMA VISÃO DISCURSIVA
}

Sandro Braga*

Resumo: Este ensaio apresenta uma perspectiva de leitura do material semiótico constitutivo da tatuagem como um gênero discursivo. Para isso, parte-se do arcabouço teórico bakhtiniano acerca dos gêneros do discurso, estabelecendo uma interface com a Análise do Discurso de corrente francesa.

Palavras-chave: discurso; gênero discursivo; tatuagem.

\section{INTRODUÇÃO}

No presente estudo, proponho uma abordagem da tatuagem como um gênero. Para isso, trabalharei com o material semiótico ${ }^{1}$ dessa técnica, ou seja, com o texto ${ }^{2}$ resultante da inserção na pele de pigmentos capazes de diferenciar determinadas regiões corpóreas. Dito de outro modo, com os desenhos, grafismos, aforismos, numerais, símbolos, que circulam socialmente, constituindo-se como formas de linguagem, ligadas às esferas da comunicação humana.

Para desenvolver essa proposta seguirei três eixos norteadores: os gêneros do discurso na teoria bakhtiniana; a tatuagem como um gênero e a relação: enunciação/enunciado - textualização/textualidade. Alerto que esses tópicos não aparecerão sequencialmente estruturados. Procurarei segui-los intercambiando-os, conforme for conveniente, para responder às questões formuladas.

\footnotetext{
* Professor do Programa de Pós-graduação em Ciências da Linguagem da Unisul. Doutor em Linguística. E-mail: <san15@ig.com.br>.

${ }^{1}$ Tomo o material semiótico não por si próprio, mas como uma linguagem, um signo ideológico.

2 Emprego o conceito de texto em sentido lato, isto é, qualquer tipo de comunicação realizada através de um sistema de signos, linguísticos ou não.
} 
Teoricamente farei uso de Bakhtin para embasar o quadro geral desta pesquisa: os gêneros do discurso, no qual as noções de enunciado e estilo também serão essenciais. Cabe dizer que, de acordo com Bakhtin (1985), estão vinculados indissoluvelmente na totalidade do enunciado, o conteúdo temático, o estilo e a composição, que são, por sua vez, determinados pela especificidade de uma dada esfera da comunicação. ${ }^{3}$ Assim, o uso da língua se dá em forma de enunciados que se diferenciam através de seus modos e espaços de produção e de circulação. Para pensar a questão do texto e da textualização, utilizo formulações propostas por Orlandi $(1988,1993,2001)$. Acredito ser possível, mesmo sabendo das dificuldades que surgirão, trabalhar com dois autores que não estão vinculados a uma mesma corrente teórica. Justifico essa opção por considerar que, tanto Bakhtin quanto Orlandi, estão, a todo tempo, envolvidos em questões que tocam a língua não por ela mesma, mas sempre inserida na interação social.

\section{OS GÊNEROS DO DISCURSO E UM OLHAR (DISCURSIVO) SOBRE A TATUAGEM}

A cena parecia rotineira, depois que se intensificou o número de sequestros em São Paulo: o ator Milhem Cortaz é obrigado a parar seu carro, durante uma noite, obedecendo a uma barreira policial. Porém, ao deixar o veículo, ele percebe uma mudança no comportamento do policial, que de repente empalidece e deixa de falar. O oficial havia notado uma tatuagem que o ator vem ostentando por conta de seu personagem, um presidiário, no filme Carandiru, dirigido por Hector Babenco: uma caveira com uma faca cravada no alto. $\mathrm{Na}$ linguagem carcerária, a figura identifica um homem que matou um policial. [...]

A produção do filme fez uma extensa pesquisa sobre os significados das tatuagens e descobriu uma forma de comunicação entre os presos. Assim, as imagens têm seu significado, desde uma ode à amada (a figura de uma mulher

\footnotetext{
${ }^{3}$ Alerto que uso duas traduções de Estética da criação verbal, de Mikhail Bakhtin: a de língua espanhola, Estética de la creación verbal, de 1985, à qual procuro ater-me, e a tradução de língua portuguesa de 1997, cf. referências.
}

BRAGA - A tatuagem como gênero... 
acompanhada do nome), passando pela religião (a imagem de Nossa Senhora) até a identificação do crime (além da caveira apunhalada, outra figura forte é a de um pênis tatuado à força nas costas do presidiário que cometeu um estupro). ${ }^{4}$

Conforme Bakhtin (1985), o uso da língua está relacionado com as diversas esferas da atividade humana. Dessa forma, o autor explica o fato de o caráter e as formas desse uso serem tão variados como as próprias esferas dessa atividade. Em sua teoria, o uso da língua se dá em forma de enunciados (orais e escritos) concretos e singulares, que emanam dos participantes de uma ou de outra esfera da atividade humana. Esses enunciados refletem as condições específicas e o objeto de cada uma das esferas, não somente por seu conteúdo (temático) e por seu estilo verbal, ou seja, pela seleção dos recursos lexicais, fraseológicos e gramaticais da língua, mas também, sobretudo, por sua composição ou construção. Bakhtin aponta que esses três elementos - conteúdo temático, estilo e construção composicional - estão vinculados indissoluvelmente na totalidade do enunciado e são determinados de modo semelhante pela especificidade de uma dada esfera de comunicação. "Cada enunciado separado es, por supuesto, individual, pero cada esfera del uso de la lengua elabora sus tipos relativamente estables de enunciados, a los que denominamos géneros discursivos" (BAKHTIN, 1985, p. 248).

Sintetizando, pode-se dizer que o enunciado é "pré-determinado" por cada esfera da comunicação humana, da mesma forma que o conteúdo temático, o estilo e a composição, pois esses estão vinculados ao todo do enunciado. A produção/circulação dos enunciados 'relativamente estáveis', dentro de cada esfera de comunicação, é o que Bakhtin chama de gêneros do discurso.

Bakhtin (2002) entende que o problema da significação é um dos mais difíceis da linguística. Um sentido definido e único, uma significação unitária, é uma propriedade que pertence a cada enunciação como um todo. Ele chama tema o sentido da enunciação completa. $\mathrm{O}$ tema deve ser único, porque do contrário não teríamos base para definir a enunciação. "O tema da enunciação é na verdade, assim como a própria enunciação, individual e não reiterável. Ele se apresenta como a

${ }^{4}$ Disponível em: <www.oestado.estadao.com.br/editorias/2002/02/28/cad029.html>. Acesso em: 30 mar. 2003. 


\section{4}

expressão de uma situação histórica concreta que deu origem à enunciação" (BAKHTIN, 2002, p. 128). O autor segue dizendo que a enunciação "Que horas são?" tem um sentido diferente cada vez que é usada e, consequentemente, na nossa terminologia, um tema diferente, que depende da situação histórica concreta em que é pronunciada e da qual constitui, na verdade, um elemento. Disso, ele conclui que o tema da enunciação é determinado não só pelas formas linguísticas que entram na composição (as palavras, as formas morfológicas ou sintáticas, os sons, as entonações), mas igualmente pelos elementos não-verbais da situação.

Essa relação que Bakhtin aponta entre conteúdo temático, estilo e composição e seus vínculos na totalidade do enunciado é fundamental para compreendermos que é através da situação de interação social que os gêneros são criados, e é através dos gêneros textuais que ocorrem as interações sociais. O tema da enunciação é concreto, assim como o instante histórico ao qual ela pertence. Somente a enunciação, em toda sua amplitude concreta, como fenômeno histórico, possui um tema. Para Bakhtin (2002), isso é o que se entende por tema da enunciação.

Neste ponto, chamo a atenção para importância da noção bakhtiniana de enunciado, para, a partir dela, abordar a questão da significação da tatuagem e, consequentemente, para apresentar a proposta de tratar a tatuagem como um gênero.

O teórico russo explica que, além do tema, ou, mais exatamente, no interior desse, a enunciação é igualmente dotada de uma significação. Por significação, diferente do tema, o autor entende os elementos da enunciação que são reiteráveis e idênticos cada vez que são repetidos. Esses elementos não têm existência concreta independente, o que não os impede de se tornarem parte indispensável da enunciação.

Aplicando a elaboração bakhtiniana à proposta deste ensaio, podese entender por que os elementos verbais e/ou não-verbais podem ser repetidos enquanto forma material, mas significam diferentemente, de acordo com a situação de interação social. É importante marcar também que essa situação de interação irá produzir aquilo que Bakhtin chama de "reação-resposta ativa responsiva". Nesse caso, atentamos para as possibilidades múltiplas de respostas ao enunciado da tatuagem quando nas esferas de comunicação. Essas múltiplas respostas estão ligadas à 
multiplicidade de significação do enunciado. Para Bakhtin (2002), a multiplicidade das significações é o índice que faz de uma palavra uma palavra.

Bakhtin (1985) aponta que a riqueza e a diversidade dos gêneros discursivos é imensa, porque as possibilidades da atividade humana são inesgotáveis e porque em cada esfera da atividade humana existe todo um repertório de gêneros discursivos que se diferencia e cresce, à medida que a própria esfera se desenvolve e fica mais complexa.

É interessante notar que usei anteriormente o termo "prédeterminado" (entre aspas), para indicar a relação do enunciado com o seu gênero e, por decorrência, com a esfera de produção e circulação. $\mathrm{Na}$ verdade, pretende-se chamar a atenção para uma ação circular entre o enunciado e o gênero do discurso, pois se na "origem" de um gênero temos os enunciados produzidos em uma situação social de interação relativamente estável dentro de uma determinada esfera social, refletindo as condições específicas e as finalidades dessa, por outro lado, os gêneros já constituídos, por terem estabilizado previamente os enunciados constitutivos dessa situação social de interação, apontarão as diretrizes de produção dos novos enunciados dessa esfera. ${ }^{5}$ Dito de outra forma, o gênero é caracterizado por uma situação sócio-histórica, que nasce das relações sociais a partir de uma certa estabilização dos enunciados. $\mathrm{O}$ gênero dá um retorno à situação de interação e é uma forma de ação que fornece os parâmetros para a constituição do enunciado.

No que tange aos elementos intrínsecos ao enunciado (conteúdo temático, estilo, composição), Bakhtin (1985) mostra que, na maioria dos gêneros discursivos (exceção feita aos gêneros literários), um estilo individual não entra na intenção do enunciado, ou seja, não serve exclusivamente às suas finalidades, sendo assim apenas seu produto complementar.

A partir do exposto e tendo em vista uma idéia preliminar da definição de gênero do discurso na teoria bakhtiniana, proponho tratar a

\footnotetext{
${ }^{5}$ Uso aspas no termo “origem" também para elucidar que não se trata de origem primeira e criadora, como um momento único.
} 


\section{6}

tatuagem, essa forma de linguagem virtual, não-verbal, inscrita na pele, como um gênero discursivo. ${ }^{6}$

Antes, porém, de apresentar esse tratamento da tatuagem como um gênero do discurso, é bom lembrar que estou tomando a tatuagem neste estudo não apenas como material semiótico, mas como forma de linguagem constituída por enunciados. Vista desse modo, pode-se falar no gênero 'tatuagem'. Como material semiótico, teríamos a pintura sob a pele, pintura essa que estou tratando como signo, portando, signo ideológico. Sendo assim, faz-se também necessário abordar a noção de signo em Bakhtin. Para esse autor (2002), a noção de signo está intrinsecamente ligada ao ideológico. Tudo que é ideológico possui um significado e remete a algo situado fora de si mesmo. Em outros termos, tudo que é ideológico é um signo. Sem signos não existe ideologia (BAKHTIN, 2002, p. 31).

O autor explica que um produto ideológico faz parte de uma realidade (natural ou social), como todo corpo físico, instrumento de produção ou de consumo, mas, ao contrário destes, os signos ideológicos também refletem e refratam uma realidade que lhe é exterior.

Vejamos mais claramente o que é o ideológico para Bakhtin (2002). Ele diz que um corpo físico vale por si próprio: não significa nada e coincide inteiramente com sua própria natureza. Nesse exemplo, não se trata de ideologia. No entanto, Bakhtin vai mostrar que todo corpo físico pode ser percebido como símbolo. Ele cita o exemplo da simbolização do princípio de inércia e da necessidade, na natureza, por um determinado objeto único.

E toda imagem artístico-simbólica ocasionada por um objeto físico particular já é um produto ideológico. Convertendo-se, assim, em signo o objeto físico, o qual, sem deixar de fazer parte da realidade material, passa a refletir e a refratar, numa certa medida, uma outra realidade. (BAKHTIN, 2002, p. 31)

$\mathrm{O}$ autor argumenta que o mesmo acontece com um instrumento de produção. Um instrumento, em si mesmo, não possui um sentido preciso, mas apenas uma função, a de desempenhar este ou aquele papel

\footnotetext{
${ }^{6}$ Opto pela denominação não-verbal para imprimir a idéia de que mesmo quando a palavra se constitui tatuagem seu campo de significação pode mudar ou ser ampliado, ou seja, deixa de significar apenas como palavra.
}

BRAGA - A tatuagem como gênero... 
na produção. É interessante notar que essa função será desempenhada sem refletir ou representar alguma outra coisa. "Todavia, um instrumento pode ser convertido em um signo ideológico: é o caso, por exemplo, da foice e do martelo como emblema da União Soviética. A foice e o martelo possuem aqui, um sentido puramente ideológico" (BAKHTIN, 2002, p. 32).

Disso, Bakhtin conclui que, ao lado dos fenômenos naturais, do material tecnológico e dos artigos de consumo, existe um universo particular, o universo de signos. E completa dizendo que um signo não existe apenas como parte de uma realidade, o signo também reflete e refrata uma outra realidade (ou seja, sua interpretação/uso pode ser cambiável), podendo distorcê-la, ser-lhe fiel, ou apreendê-la de um ponto de vista específico. "Todo signo está sujeito aos critérios de avaliação ideológica (isto é: se é verdadeiro, falso, correto, justificado, bom, etc.)" (BAKHTIN, 2002, p. 32). Dessa forma, o domínio ideológico coincide com o domínio dos signos, ou seja, os dois domínios são mutuamente correspondentes. Essa explicação é fundamental para diferenciarmos material semiótico (apenas uma pintura) da relação de significação que essa imagem pode produzir. Para produzir significação é preciso ser signo. Para Bakhtin, ali onde o signo se encontra, encontra-se também o ideológico e tudo que é ideológico possui um valor semiótico de representação.

É pensando a partir do signo ideológico refletido e refratado através do material semiótico, concretizado pela tatuagem, que pretendo tratar essa forma de materialidade virtual como um gênero do discurso, realizado dentro de uma certa esfera da práxis humana.

Conforme Bakhtin (2002), cada signo ideológico não é apenas um reflexo, uma sombra da realidade, mas também um fragmento material dessa realidade. Assim, cada fenômeno que funciona como signo ideológico tem uma encarnação material, seja como som, como massa física, como cor, como movimento do corpo ou como qualquer outra forma de materialidade.

Nesse sentido, introduz a tatuagem como um signo de escrita ou de inscrição, cuja materialização está no corpo, constituindo parte intrínseca desse signo. É a junção de traços, tintas e pele que faz com que aquela determinada região corpórea, antes "limpa" ou "vazia", passe 
a simbolizar semanticamente outra coisa. Essa outra coisa, seja desenho, grafismo, aforismo, passará a refletir e refratar toda carga ideológica que esse signo agrega.

De acordo com Bakhtin (2002), a realidade do signo é totalmente objetiva e, portanto, passível de um estudo metodologicamente unitário e objetivo. Um signo é um fenômeno do mundo exterior. O próprio signo e todos os seus efeitos - todas as ações, reações e novos signos que ele gera no meio social circundante - aparecem na experiência exterior.

É importante alertar para um fato: estou falando, neste momento, de representação/manifestação ideológica através da tatuagem de forma genérica. Não estou entrando, ainda, nas particularidades de significação que cada tatuagem pode ter ou adquirir em cada corpo ou até mesmo nos diferentes lugares de circulação de um mesmo corpo. Digo isso, porque a tatuagem, observada isoladamente, vista como material semiótico e como texto, pode ser reiterada, repetida, mas não como enunciado. Ou seja, o enunciado é unidade do discurso, portanto único e irrepetível.

A teoria bakhtiniana (1985) aponta para a existência de dois grandes grupos de gêneros discursivos: os gêneros primários ou simples e os gêneros secundários ou complexos. Os primários são aqueles que se constituíram na comunicação verbal cotidiana (os tipos de diálogo oral, como a linguagem das reuniões sociais, dos círculos, linguagem familiar, cotidiana, o bilhete, a carta familiar, etc.). Os gêneros secundários são os que aparecem em comunicações culturais mais complexas e relativamente mais desenvolvidas, principalmente escritas: os gêneros das esferas artística, científica, sociopolítica, etc.

Bakhtin (1985) destaca a importância dessa diferenciação (gêneros primários e secundários), pois a inter-relação entre os gêneros primários e secundários de um lado e o processo histórico de formação dos gêneros de outro, é o que esclarece a natureza do enunciado; e, além disso, o autor aponta o difícil problema da correlação entre língua, ideologias e visões de mundo.

Aqui, pretendo entrar num ponto nevrálgico deste trabalho: partindo da idéia de um tratamento discursivo à tatuagem, em qual desses dois grandes grupos caberia incluí-la, como gênero primário ou secundário? 
Se compararmos a tatuagem a uma linguagem do cotidiano, como, por exemplo, a carta, que transmite uma comunicação simples, poderíamos considerar a tatuagem como um gênero primário. Mas, por outro lado, se considerarmos que durante o processo de formação dos gêneros secundários, esses absorvem e transmutam os gêneros primários, de todas as espécies, que se constituíram em circunstâncias de uma comunicação verbal espontânea, ou seja, se considerarmos que os gêneros primários, ao se tornarem componentes dos gêneros secundários, transformando-se dentro destes e adquirindo uma característica particular, perdem sua relação imediata com a realidade existente e com a realidade dos enunciados alheios, poderíamos ver a tatuagem com gênero secundário. Bakhtin (1985) cita o exemplo da réplica do diálogo cotidiano ou da carta inserida num romance. Nesses casos, diálogos e cartas perdem sua relação imediata com a realidade existente e com a realidade do cotidiano para se tornarem acontecimentos da esfera de ideologia especializada. No entanto, nesse exemplo, é importante deixar claro que o gênero secundário é o romance e não o diálogo ou a carta inserida no romance.

Assim, para decidirmos em qual desses grupos poder-se-ia incluir essa atividade da comunicação humana - a tatuagem - tratada aqui como um gênero discursivo, é importante termos claro que a divisão entre gêneros primários e secundários é ideológica e, portanto, histórica. Os gêneros secundários correspondem àquelas ideologias sistematizadas e formalizadas.

Após essas diferenciações, proponho analisar os enunciados formados a partir desse material semiótico, constituído virtualmente por signos ideológicos, sob duas perspectivas: a primeira, a qual acredito ser a principal, é considerar a tatuagem como um gênero primário. Essa categoria de gênero é a de maior ocorrência, fazendo parte dela toda gama de enunciados materializados por signos através da tatuagem, cuja circulação não pertence à categoria "instituição formalizada", ou seja, os signos são utilizados de forma semelhante aqueles que objetivam as comunicações cotidianas. No entanto, acreditamos ser possível uma segunda abordagem para os enunciados emergentes desse material

\footnotetext{
${ }^{7}$ Esse é um termo que que Bakhtin utiliza para se referir aos gêneros das esferas artística, científica, sociopolítica, etc.
} 
semiótico, que se pode considerar como gênero secundário. Nessa outra abordagem, tem-se a transmutação dos enunciados oriundos da comunicação cotidiana para uma prática especializada. Falo da tatuagem vista não mais como signo ideológico da práxis diária de comunicação e sim daquela destinada às especificidades dessa técnica (nesse caso, vista como arte), voltada a concursos, produção de revistas especializadas, etc. Como gênero secundário a tatuagem faria uso da linguagem do cotidiano, que por sua vez seria transformada, aparecendo resignificada em outra esfera de uma comunicação cultural. Conforme já dito, durante o processo de formação dos gêneros secundários, estes absorvem e transmutam os gêneros primários que os compõem.

Mesmo trabalhando com duas possibilidades de entrada nos gêneros discursivos (primários e secundários), a idéia de tratar a tatuagem como gênero parece ganhar força, pois se pode concebê-la como parte constitutiva de uma atividade de comunicação humana, que comporta um material semiótico concreto. Material esse que se constitui em enunciados dentro de uma entidade sócio-histórica, possibilitando uma ação dialógica.

Consciente de que será difícil sustentar essa dicotomia dentro de um mesmo gênero discursivo, chamo a atenção para a necessidade de se ter claro que nessas duas esferas de realização da atividade humana circulam enunciados ideologicamente diferentes. Somente apontando essas diferenças, penso estar sendo fiel a Bakhtin (1997), quando ele fala que não podemos ignorar a natureza do enunciado, tampouco as particularidades dos gêneros, que assinalam a variedade do discurso em qualquer área do estudo linguístico. Ou seja, não podemos desvirtuar a historicidade do estudo para não enfraquecer o vínculo existente entre a língua e a vida. "A língua penetra na vida através dos enunciados concretos que a realizam, e é também através dos enunciados concretos que a vida penetra na língua" (BAKHTIN, 1997, p. 282).

\section{ENUNCIADO E ESTILO: AS RELAÇÕES COM O SENTIDO}

O tratamento que darei à tatuagem está ligado ao seu uso ideológico e à significação adquirida na formação textual do gênero, em

BRAGA - A tatuagem como gênero... 
que os signos não significam por eles mesmos. Neste caso, pode-se falar do sentido no enunciado proposto por essa prática de grafar o/no corpo.

Considerando a tatuagem e a historicidade de sua formação, não se pode deixar de lado o que Bakhtin fala sobre o estilo:

O estilo está indissoluvelmente ligado ao enunciado e às formas típicas de enunciados, isto é, aos gêneros do discurso. O enunciado - oral e escrito, primário e secundário, em qualquer esfera da comunicação verbal - é individual, e por isso pode refletir a individualidade de quem fala (ou escreve). (BAKHTIN, 1997, p. 282-283). ${ }^{8}$

Bakhtin (1997) alerta que nem todos os gêneros são igualmente aptos para refletir a individualidade do autor/emissor no enunciado, ou seja, nem todos são propícios ao estilo individual. Ele aponta que os gêneros do discurso menos favoráveis para refletir a individualidade na língua são os que requerem uma forma padronizada, os documentos oficiais, por exemplo. Para Bakhtin, os gêneros literários são os mais propícios. Neles, o estilo individual faz parte do empreendimento enunciativo enquanto tal e constitui uma das suas linhas diretrizes. Com esse mesmo raciocínio, entendo que a tatuagem também pode ser tomada como um gênero altamente capaz de refletir a individualidade do autor, através (pelo) do enunciado. ${ }^{9}$

A variedade dos gêneros do discurso pode revelar a variedade dos estratos e dos aspectos da personalidade individual, e o estilo individual pode relacionar-se de diferentes maneiras com a língua comum. "A definição de um estilo em geral e de um estilo individual em particular requer um estudo aprofundado da natureza do enunciado e da diversidade dos gêneros do discurso" (BAKHTIN, 1997, p. 283).

Para melhor compreendermos o que seria o estilo, ou melhor, a relação do estilo com o enunciado, já que ambos são pré-determinados pelo gênero discursivo de dada esfera da comunicação, vejamos antes a questão da significação. Como dito, Bakhtin (2002) considera o problema da significação como um dos mais difíceis da linguística. Assim

\footnotetext{
8 Utilizo o termo 'historicidade' compreendendo-o como o processo de história de cada tatuagem individual e o termo 'historicização' como o processo histórico dessa prática.

${ }^{9}$ Entendo como sendo autor, neste caso, não quem realiza a técnica de tatuar, mas a pessoa que porta a tatuagem, ou seja, quem traz em si um projeto discursivo.
} 
como o próprio autor propõe, em Marxismo e filosofia da linguagem, limitarme-ei a uma análise superficial da questão. Conforme esse teórico russo, um sentido definido e único, uma significação unitária, é uma propriedade que pertence a cada enunciação como um todo. Vimos também que ele chama o sentido da enunciação completa de tema.

Esse termo é, naturalmente, sujeito a dúvidas. Para nós, o termo "tema" recobre igualmente sua realização; é por isso que ele não deve ser confundido com o tema de uma obra de arte. $\mathrm{O}$ conceito de "unidade temática" é o que estaria mais próximo do nosso. (BAKHTIN, 2002, p. 128, grifo do autor)

O tema da enunciação é, assim como a própria enunciação, individual e não reiterável. O tema se apresenta como a expressão de uma situação histórica concreta que deu origem à enunciação. "O tema da situação é concreto, tão concreto como o instante histórico ao qual ela pertence. Somente a enunciação tomada em toda sua amplitude concreta, como fenômeno histórico, possui um tema. Isto é o que se entende por tema da enunciação" (BAKHTIN, 2002, p. 129).

Bakhtin afirma ainda que o tema é um sistema de signos dinâmico e complexo, que procura adaptar-se adequadamente às condições de um dado momento da evolução. Para ele, "o tema é uma reação da consciência em devir ao ser em devir. A significação é o aparato técnico para a realização do tema" (BAKHTIN, 2002, p. 129). Conforme o autor, é impossível traçar uma fronteira mecânica absoluta entre a significação e o tema, assim, não há tema sem significação, e vice-versa.

Voltando à questão do estilo, segundo Bakhtin (1985), o vínculo indissolúvel, orgânico, entre o estilo e o gênero mostra-se com grande clareza quando se trata do problema de um estilo linguístico ou funcional. $\mathrm{O}$ estilo linguístico ou funcional nada mais é do que o estilo de um gênero peculiar a uma dada esfera de atividade da comunicação humana. Cabe a cada esfera conhecer seus gêneros, apropriados à sua especificidade, aos quais correspondem determinados estilos.

Pensando na tatuagem, pode-se dizer que uma função (sociocultural e/ou estética) e certas condições específicas em uma esfera 
da comunicação geram um certo gênero, ou seja, um certo "tipo" histórico de enunciado, relativamente estável do ponto de vista temático, composicional e estilístico. Neste sentido, recorro a Bakhtin para pensar o estilo como indissociavelmente vinculado a unidades temáticas e composicionais determinadas: tipo de estruturação e de conclusão de um todo. Tem-se de pensar, também, na relação entre o autor e os outros parceiros da comunicação, como sendo a relação entre a tatuagem que se faz sujeito, pelo sujeito, tornando-se enunciador. Em "os outros" incluíse os parceiros da comunicação de que fala Bakhtin, mas gostaria de poder falar, também, dos que não se constituem como interlocutores (estamos tratando interlocutores não segundo o conceito da $\mathrm{AD}$, mas como destinatário preferencial). Nesse sentido, pensar a tatuagem como gênero torna-se complexo e desafiador, pois, diferentemente de uma atividade oral ou escrita da língua, que se materializa, de uma forma ou de outra, fora do sujeito, a tatuagem está para o sujeito assim como o sujeito para a tatuagem, trata-se de um atravessamento de mão-dupla. Parece difícil conceber uma atividade verbal oral fora do sujeito. Grosso modo, estamos pensando na possibilidade de isolar a "fala" depois de falada, assim como a escrita depois do ato de escrever. Diante do exposto, podemos diferenciar essas atividades (oral e escrita) da tatuagem, que somente pode ser assim chamada a partir do ato de inserção do signo na pele e de sua permanência no sujeito.

Disso, temos o corpo não apenas como suporte textual, mas, sobretudo, como mídia constitutiva do enunciado, determinando sua produção e circulação. Ou seja, indicando onde esse material semiótico entrará como signo ideológico comunicativo. E é essa interação na práxis da atividade humana que caracteriza o estilo e, concomitantemente, o enunciado desse gênero discursivo. Consequentemente, esse gênero adquire uma "certa estabilidade", passando a "pré-determinar" a formação de novos enunciados dentro do mesmo gênero.

Para Bakhtin (1985), o estilo entra como elemento na unidade do gênero de um enunciado. Assim, para se fazer um estudo da estilística da língua é necessário, para ser mais adequado e produtivo, partir-se do fato de que os estilos da língua pertencem, por natureza, ao gênero e esse estudo deve basear-se no estudo prévio dos gêneros. 


\section{4}

\section{ENUNCIAÇÃO/ENUNCIADO: TEXTO/TEXTUALIZA- ÇÃO/TEXTUALIDADE}

Para se pensar a tatuagem como um gênero, faz-se necessário lançar um olhar sobre sua textualização, ou seja, sobre a circulação dos sentidos, os modos pelos quais as inscrições passam a significar dentro de um gênero específico. Para essa abordagem, faço uso da noção de textualidade de Orlandi (2001) que, mesmo adotando uma noção de discurso filiada à $\mathrm{AD}$ francesa, que se diferencia um pouco da noção bakhtiniana, será útil para dar um tratamento de texto a tatuagem. Vale lembrar que, no escopo bakhtiniano adotado neste artigo, a tatuagem seria um enunciado.

Orlandi (2001, p. 203-204) relata a queixa de uma antropóloga, que se questionava por que os índios (naquele caso, os índios Assurini) aprendem a escrever. A própria antropóloga contou que eles escreviam bilhetes entre si - do gênero correio amoroso - o que incomodava os envolvidos no projeto sobre cultura indígena. Orlandi não vê problema nesse fato, tampouco o vê como deturpação da cultura indígena, justificando que o bilhete, ou, mais amplamente, a escrita, é uma forma de relação social. "Ela estrutura relações." Outra angústia da antropóloga era a de que os Assurini agora escreviam, "melhor dizendo, inscreviam a escrita de" nomes próprios no corpo, fato que a pesquisadora lastimava, uma vez que trabalhava com pintura corporal e não apreciava ver substituídos os traços da pintura por letras na pele. Orlandi novamente se posiciona contrária, pois, para a autora, os índios estariam tratando as letras como grafismo.

A meu ver, independentemente de a marcação corporal estar sendo tomada como "letras", palavras (nomes próprios) e/ou como grafismo ou desenho, isso é o que menos importa para o tratamento que queremos dar à tatuagem como um gênero. Seja qual for a forma de sua realização, o importante é ter-se a idéia de texto, ou melhor, de textualização, onde o que está ali inserido na pele passa a significar de forma única, podendo ser repetível enquanto forma, mas jamais reiterado enquanto enunciado, ou seja, sempre significando diferentemente em sua textualidade, tal como propõe Bakhtin com a noção de enunciado, único e irrepetível. 
Conforme Orlandi, na nossa cultura ocidental, letrada e cristã, a letra é o traço da entrada no simbólico. "Traço que marca o sujeito enquanto sujeito, em sua entrada de autoria, frente à escrita" (ORLANDI, 2001, p. 204).

A partir do exposto, pode-se pensar também a questão da autoria na tatuagem. Quem é o autor do quê? O tatuador ou o sujeito tatuado? Acredito ser uma questão para bastante reflexão; mesmo não sendo o escopo deste ensaio, pode-se deixar algumas pistas para investigações futuras. Como disse, o enunciado não pode ser repetido em sua textualização, e é ele que fornece sentido único ao texto (tatuagem). Assim, cabe a posição de autoria ao sujeito que é tatuado, ao corpo que se torna superfície midiática e materialidade semiótica. Não podemos atribuir autoria ao tatuador, porque se assim fizéssemos estaríamos atribuindo posição de autor a alguém que não participa do enunciado num todo, ou seja, não possui uma relação com o signo ideológico e com a significação eminente deste signo; é como se estivéssemos atribuindo autoria ao escriba. Dito de outra forma, todo enunciado tem um autor, mas esse autor não é sinônimo de quem redigiu ou proferiu (ou no caso da tatuagem, quem desenhou), e, sim, de quem assume seu projeto discursivo. É uma posição dialógica, diante da qual se pode responder também dialogicamente.

Orlandi (2001) também chama a atenção para essa diferença de repetição. A tatuagem se individualiza, embora os traços sejam os mesmos, no modo como são praticados por/em cada corpo: o corpo místico, o corpo atlético, o corpo adolescente... Não é somente a diferença entre o proprietário do corpo que constituirá o que estou chamando de textualização da tatuagem, também a parte do corpo em que ela está inserida será fundamental no processo de significação. $\mathrm{O}$ órgão tatuado poderá indicar, por exemplo, o seu leitor/destinatário preferencial. Um desenho grafado na parte superior da mão poderá significar $\mathrm{X}$, enquanto que o mesmo desenho inserido no púbis significará Y. Assim, braços, pernas, rosto, costas, peito, nariz, orelhas, pés, genitais, boca, umbigo são diferentes superfícies que constituem diferentes materialidades, diferentes modos de enunciação, que indicam novas formulações e circulação de sentidos ou, como prefere Orlandi, diferentes formas de textualidade. " $\mathrm{E}$ manifestam todas elas nossos modos de relação com o simbólico. Mais especificamente em sua 


\section{6}

dimensão textual" (ORLANDI, 2001, p. 204). Assim, como já dissemos anteriormente, o corpo não é apenas suporte para o material semiótico, que Orlandi chama de texto; o corpo, ou melhor, cada região do corpo, faz parte da constituição desse material semiótico, é parte composicional do texto.

Além dos diferentes lugares (corporais) de enunciação, outras diferenças podem ser levantadas e incidirão significativamente na atribuição dos sentidos de uma tatuagem: o tamanho da letra e/ou desenho, a espessura dos traços, a intensidade das cores, e, claro, a técnica do tatuador, que imprimirá traços mais ou menos precisos.

É nesse sentido que Orlandi (2001) fala que a entrada no simbólico é fatal. As suas formas produzem diferentes efeitos de sentido. Nada é indiferente na instância do significante. A autora aponta, no caso dos índios Assurini, que a relação com as letras migra para as suas diferentes experiências de linguagem, sendo a arte a dominante. A significação acontece no corpo, nesse lugar material, lugar de inscrição, manifestação do grafismo, da pintura, do texto. Aqui, é importante ressaltar que essa entrada no simbólico através da pintura de letras continua tomando o corpo como mídia para essa produção, cujo efeito pode ser o estético, diferentemente de quando os índios escrevem em outras mídias (pensamos na escrita dos livros didáticos ou mesmo dos bilhetes).

Diante dessas considerações, cabe a pergunta: como "ler" a tatuagem como um texto? É preciso, antes de tudo, não direcionar o olhar puro e simples para a tatuagem isoladamente, como se ela fosse um desenho qualquer, sobre uma folha de papel qualquer (no caso do desenho no papel teríamos outra enunciação, outra textualidade e outro texto). É preciso olhar, como já argumentei, para a sua textualização. Nesse caso, a interpretação está posta no próprio corpo, constituindo um acréscimo na superfície da pele, formando um "mais" corporal, tornando a carne textualizada. E é essa interferência no corpo que vai atribuir um significado ao corpo e não outro. É isso, também, que vai dar o que estou chamando de "certa estabilidade" de atribuição de sentido ao corpo através do enunciado. Ou seja, atribuindo sentido a um corpo individual, através de uma relação com o social. E que possibilita classificar a tatuagem como um gênero discursivo. 
Vale lembrar que estou trabalhando com o conceito de texto em sentido lato, que manifesta a capacidade textual/representativa do ser humano, isto é, qualquer tipo de comunicação realizada através de um sistema de signos, portanto, qualquer manifestação ideológica. Todos nós temos interiorizado um conjunto de textos, relativamente estáveis, com determinadas características específicas. Os textos desempenham papel fundamental em nossa vida social, já que estamos nos comunicando o tempo todo. No processo comunicativo, eles têm uma função e cada esfera de utilização da língua, cada campo de atividade, elabora determinados tipos de textos que são estáveis, ou seja, repetemse, tanto no assunto como na função, no estilo, na forma. É isso que nos permite reconhecer um texto como uma bula de remédio ou uma notícia jornalística, por exemplo. No entanto, como já mencionado, os enunciados desses textos não são repetíveis, e o enunciado é essencial para produção de sentido.

O que é falado, escrito ou desenhado, a maneira como isso é feito, a forma que é dada ao texto, são características diretamente ligadas ao gênero. Como as situações de comunicação em nossa vida social são inúmeras, inúmeros são os gêneros textuais: bilhete, carta pessoal, carta comercial, e-mail, etc., e aqui quero incluir a tatuagem.

Esta proposta de inclusão da tatuagem como gênero, justifica-se porque se sabe que identificar o gênero textual é um dos primeiros passos para uma competente leitura do texto. No caso da tatuagem, é importante identificar o que está estabilizado como tatuagem, pois, dessa forma, pode-se compreender o retorno que esse gênero possibilita como forma de resposta-ativa responsiva. Nos exemplos que trarei do uso da tatuagem em presídios, percebe-se uma marca de escrita do "eu", em uma determinada situação de relação social, diferente do uso contemporâneo (de tatuagens) pelos jovens, pois, nesse caso, nota-se o uso desses signos ligado mais fortemente pela valoração estética. ${ }^{10}$

Para Orlandi (2001), a variante é a base da textualidade. A autora exemplifica essa asserção com os diferentes sentidos que são atribuídos às canções de Zeca Baleiro através de pequenas versões que o compositor faz de outras músicas, onde a substituição de apenas uma

${ }^{10}$ Falo em escrita do eu no sentido de uma historicidade de cada tatuagem marcada no corpo e a relação dessa marca com a vida carcerária. 


\section{8}

palavra faz deslizar os sentidos, sob efeitos metafóricos, em novas formulações que jogam como paráfrases.

Da mesma forma a variante também é a base da textualidade na tatuagem. Como já dito, a letra ou grafismo, desenho concreto ou tribal, superfície plana ou multidimensional, a cor da pele, a textura da pele (ter pêlos ou não), tudo isso será levado em conta na formação da textualidade, atestando o funcionamento ideológico da linguagem (Orlandi fala em formações discursivas, que não pretendemos discutir neste trabalho). "Toda essa profusão de textos que se avolumam - seja pelas novas tecnologias, ou pelas distintas superfícies que exploram, em novas formas de significar o corpo - apontam para diferentes modos do sujeito (se) viver o social" (ORLANDI 2001, p. 206).

Cabe lembrar que, mesmo com todos os artefatos que se avolumam, como cita Orlandi, isso não impede a relativa estabilização do gênero. Novos artefatos podem contribuir para modificações no gênero, mas que, por sua vez, também passarão por um processo de estabilização. É como se certos enunciados criassem o gênero e depois esses enunciados, já estabilizados, dessem um retorno ao gênero e viceversa. Ou seja, certos enunciados criam os gêneros e os gêneros configuram os enunciados.

Assim, a tatuagem configura-se num gênero discursivo que só pode ser analisado num todo: em todo plano enunciativo, no qual a tatuagem está inserida no corpo da pessoa tatuada. Referimo-me, aqui, ao trabalho de Ramos (2001), Teorias da tatuagem, que se propõe a discutir a tatuagem dentro de uma abordagem semiótica. Boa parte do trabalho da autora fica comprometida por focalizar a tatuagem apenas em sua forma de desenho, fotografada em close up. As fotos estampadas no livro, em sua maioria, não retratam o que estou tomando como "plano enunciativo", que é constituído pelo corpo em sua plenitude. E não se trata somente do corpo físico, pois, para se fazer uma análise mais adequada, teríamos que atentar para o contexto social em que essa corporeidade está inserida. Outra parte do livro prende-se à constituição da tatuagem do ponto de vista do tatuador. Mostra, de forma eficaz, a localização espaço temporal de dois tatuadores profissionais, porém, 
deixa de fazer, em parte, a mesma contextualização de quem se tatua. ${ }^{11}$ No caso do trabalho referido, é como se tentássemos entender uma crônica retirada de seu lugar de circulação, que geralmente é o jornal. A crônica fora do jornal corre sérios riscos de não ser compreendida da mesma forma que seria por seus leitores no jornal diário. ${ }^{12}$

Resumindo, o olhar à tatuagem é feito em uma dupla inserção. Não se pode focá-la fazendo um recorte apenas do desenho ou do grafismo subscrito na pele. É necessário estender-se sobre a tatuagem, vazando-a de seus limites gráficos e compreendê-la como algo que surge de uma situação sócio-histórica; ou seja, como signo ideológico, que nasce das relações sociais. Classificar a tatuagem como um gênero discursivo é observar a existência de uma certa estabilização dessa manifestação social. Uma certa estabilização que acaba por criar o gênero que, por sua vez, dá um retorno à produção e recepção dos novos enunciados. É uma forma de ação que dá o tom do enunciado. Assim, a tatuagem como gênero deixa de ser vista como um aparato formal para ser considerada como entidade sócio-histórica e forma de ação.

É interessante notarmos o uso da tatuagem em culturas diferentes, pois os enunciados que circulam numa e noutra cultura também serão diferentes e a produção de sentido estará diretamente imbricada nesses enunciados. Outro exemplo a ser citado é o uso da tatuagem em nossa sociedade ocidental. Há cerca de 30 trinta anos, esse uso era restrito às pessoas marginalizadas socialmente, por exemplo, pessoas nas prisões; consequentemente, esses signos ideológicos produziam um efeito de sentido negativo nessa sociedade. Hoje, entretanto, o uso da tatuagem está difundido, sobretudo entre jovens, muitas vezes adicionado ao uso de piercings, produzindo, sobretudo, um efeito estético, mas não menos significativo. Note que, nesse outro momento histórico, a relação desses signos ideológicos com a sociedade é outra, ou seja, a mudança histórica modifica o significado ideológico do gênero, reforçando assim a posição bakhtiniana de que um signo não existe apenas como parte de uma realidade, ele também reflete e refrata outra.

\footnotetext{
${ }^{11}$ A análise está centrada na loja Stoppa Tatoo da Pedra, localizada em Florianópolis e nos profissionais que lá trabalham.

12 Acrescento a palavra "diário", porque o tempo também constitui um dos fatores de inteligibilidade da crônica.
} 
Nos exemplos a seguir, pode-se perceber mais claramente como se dá a relação do enunciado e a produção de sentido. A revista Trip publicou uma matéria especial acerca das tatuagens dos presidiários do Carandiru. De saída, chamo a atenção para a chamada da reportagem: "TRIP se infiltrou no arquivo fotográfico de um dos prédios menos populares e mais crowdeados do país. Nas próximas páginas, as tatuagens do CARANDIRU”. ${ }^{13}$ Nota-se que a chamada já aponta para o lugar de circulação da tatuagem como enunciado, e mais, o lugar social de sua constituição. Diferentemente do trabalho de Ramos (2001), a tatuagem não é analisada do ponto de vista apenas do desenho.

O ano, 1920. Data de inauguração do maior complexo presidiário da América Latina, a Casa de Detenção de São Paulo. Mil prisioneiros são transferidos de outros cárceres para descabaçar o novo buraco. Entre estupradores, homicidas, estelionatários, bandidos, foras da lei das mais diversas especialidades, o médico psiquiatra de plantão resolve, por conta própria, criar uma seção de criminologia. Moraes Mello, o tal doutor, acaba se apaixonando por um tema que viria a se tornar fixação na sua vida: as tatuagens dos presidiários. Para felicidade dos tatoo lovers, Mello registrou e analisou mais de 3 mil imagens perpetuadas nas peles de mentes criminosas. O resultado é fascinante. ${ }^{14}$

A reportagem, que se constitui de matéria escrita mais fotos, retrata a inserção da tatuagem, no corpo dos presidiários, congruente com suas personalidades.

As tatuagens vão além do prazer pela estética pura. As imagens delatam traços da personalidade do criminoso. Cada uma tem um significado específico, que só quem vivia no presídio flagrava. Há tatuagens que mostram quais as especialidades do detento no mundo do crime. Outras que identificam suas preferências sexuais. ${ }^{15}$

Novamente, enfatizo que tanto as formas dos desenhos como os lugares corporais onde eram feitos são decisivos na atribuição do

\footnotetext{
13 TRIP nº. 58. Disponível em: <www.2.uol.com.br/trip/58/tattoo/txt.htm>. Acesso em 30 mar. 2003.

${ }^{14} \mathrm{Cf}$. a nota 13.

${ }^{15}$ Cf. a nota 13.
}

BRAGA - A tatuagem como gênero... 
significado à tatuagem, ou seja, a atribuição de sentido ao signo ideológico. Pontos tatuados na mão entre o polegar e o indicador mostram, por exemplo, de que tipo de bandido se trata. É um ponto para o batedor de carteira, dois para o estuprador, três para o traficante, quatro e cinco para ladrões. Dependendo da disposição dos pontos, é possível ainda saber a posição na hierarquia da quadrilha. Já um coração com a frase "Amor de mãe" revela homossexualidade passiva, assim como borboletas, sereias e pontos no rosto. Naquela época, todo estuprador tinha a figura de um pênis desenhada nas costas. Isso facilitava sua identificação por todos no presídio. Ter uma tatuagem dessas significava longos e terríveis anos de servidão sexual na cadeia, uma vez que estupradores nunca foram bem vistos nos cárceres. Nem sempre as sessões de tatuagem eram feitas com o total consentimento do tatuado. Em alguns casos, usava-se a força. Note-se que, nesses casos, tem-se um enunciado sem o consentimento da pessoa tatuada. Pode-se sugerir, pensando no conceito de autoria de Bakhtin (2002), que se trata de uma autoria coletiva dentro de uma determinada esfera da comunicação. E, ainda, que ocorre uma categorização dentro do presídio, como meio de controle.

Além disso, chamo a atenção para a seguinte citação da revista, que trata de distinguir as tatuagens do início do Carandiru e as de hoje. ${ }^{16}$

As tatuagens dos presos do Carandiru de 70 anos atrás nada têm a ver com as tatuagens dos presos de hoje. [...] "Não acredito que os presos de hoje em dia saibam o que significam as imagens gravadas em seus corpos. Na maioria das vezes, as tatuagens são feitas do lado de fora dos muros, por pura vaidade mesmo. Essa coisa da tatuagem ter um significado é do passado. O trabalho do doutor Mello é brilhante", diz o médico Dráuzio Varella... ${ }^{17}$

Apesar da opinião de Varella, acredito que não importa se os significados das tatuagens não são mais os mesmos de anos atrás. Insisto que elas hoje também têm seus significados. Trata-se de um outro processo de significar, que se constrói a partir de outros enunciados já formulados, que, por sua vez, estão significando outras coisas advindas

\footnotetext{
${ }^{16} \mathrm{O}$ uso do advérbio de tempo "hoje" é recurso para ser fiel à reportagem, datada no ano de 2002, lembrando que o complexo Carandiru foi implodido no final daquele mesmo ano (08/12).

${ }^{17}$ Cf. a nota 13.
} 


\section{2}

de outras relações sociais. É o que chamo de relação do significado com a historicidade. Se pensarmos nas tatuagens carcerárias, podemos alegar que a criminologia de hoje também pouco tem a ver com a criminologia de 70 anos atrás. E são essas situações de interação entre os sujeitos que vão possibilitar a construção de outros enunciados sócio-históricos. Segundo Bakhtin, "as formas do signo são condicionadas tanto pela organização social de tais indivíduos como pelas condições em que a interação acontece" (BAKHTIN, 2002, p. 44). É importante ressaltar também que não é a forma de significar que constitui o gênero tatuagem: é a estabilização da significação que dará uma ação de retorno ao gênero e ao enunciado, levando em conta, é claro, a interação social.

Destaco, ainda, que conforme o funcionamento ideológico, outras formas de sociabilidade e/ou outras formas de manifestação dos conflitos podem ocorrer. Isso é importante para se pensar a significação como não sendo uma significação " $X$ " única possível. Aqui, refiro-me à relação dialógica bakhtiniana centrada na existência de um outro, em que a todo "dizer" corresponde uma ação de reação-resposta ativa responsiva. Bakhtin nos alerta que também esse dizer primeiro (se é que é possível assim falar) não é aleatório; está estruturado, ou melhor, planejado, e esse dizer gerará um(s) outro(s) dizer(es).

Nesse sentido, a tatuagem também terá respostas ativas, às quais poderão ser atribuídos sentidos diferentes. E essa atribuição de sentidos marcará decisivamente o social; sociabilização ou confronto, pensando sempre que o homem é um ser que interpreta e é interpretado, inclusive a ele próprio. "O homem é um animal que olha o seu corpo pensando em outro e olha o corpo do outro pensando no seu. A imagem humana é sempre um corpo diante do espelho" (PERUZZOLO, 1998, p. 14).

Voltando à questão da significação, é importante - e no caso da tatuagem isso fica muito claro - a historicidade social do sujeito (que se tatua). O sentido de uma tatuagem realizada numa dada época poderá não corresponder em uma outra, mesmo pertencendo à mesma pessoa. E, nesse caso, é interessante pensar que o efeito de sentido é produto da textualidade ali exposta, que terá uma relação direta com o social. Nessa perspectiva, evidencia-se a relação da tatuagem - linguagem - como marca definitiva (a prior). Uma tatuagem feita na adolescência produzirá um determinado texto e sua textualidade, um enunciado, ao qual serão atribuídos determinados efeitos de sentido. Consequentemente, essa 
textualidade terá uma relação com um auditório específico, possibilitando uma leitura, também específica. "Toda leitura tem sua história" (ORLANDI, 1988, p. 41). O mesmo acontecerá com essa mesma tatuagem quando o sujeito (tatuado) estiver na idade adulta. No entanto, o mesmo texto terá outra textualidade, formada a partir de um outro enunciado, e suas relações com o social provavelmente serão outras. Nota-se a importância disso nos conceitos bakhtinianos de sujeito histórico e social. Observemos o que diz Orlandi com referência à leitura de um texto.

Para um mesmo texto, leituras possíveis em certas épocas não foram em outras, e leituras que não são possíveis hoje serão no futuro. Isto pode ser observado em nós mesmos: lemos diferentemente um mesmo texto em épocas (condições) diferentes. (ORLANDI, 1988, p. 41)

Os lugares de enunciação desse novo enunciado serão cruciais para o sujeito (tatuado) decidir se permanece com a tatuagem ou se ele se submeterá a algum processo de apagamento. Também essa decisão faz parte do processo de significação desses textos (corpos) e, logo, do processo de sua compreensão, portanto, nos termos bakhtinianos a uma reação ativa responsiva.

A questão do apagamento da tatuagem também renderia ótimas reflexões. Poder-se-ia perguntar o que leva o sujeito (tatuado) à retirada desse texto do seu corpo? E o apagamento, por si só, não produziria um outro enunciado e outras significações ao corpo? As cicatrizes seriam novas marcas de significação? Poder-se-ia pensar o que estaria o sujeito deixando de enunciar ou enunciar-se? Orlandi (1993) trata da questão das Formas do silêncio, da significação do silêncio, ou seja, do que se quer dizer quando não se diz nada. Da mesma forma, podemos pensar no apagamento da tatuagem como uma nova forma de significação, uma vez que, conforme Orlandi (1993), a nossa sociedade tem urgência do dizer e estamos inseridos em práticas significantes que expõem o sujeito a uma visibilidade constante. Estamos imersos em uma grande quantidade de símbolos, e os produzimos em permanência. No entanto, do mesmo modo como mudam as condições de significar, mudam também as formas como o sujeito se posiciona nos trajetos da significação. 


\section{REFERÊNCIAS}

BAKHTIN, M. M. Estética da criação verbal. São Paulo: Martins Fontes, 1997.

Estética de la creación verbal. 2. ed. México: Siglo Veintiuno, 1985.

BAKHTIN, M. (VOLOCHINOV, V. N.). Marxismo e filosofia da

linguagem. 10. ed. São Paulo: Hucitec, 2002.

ORLANDI, E. P. Discurso e texto: formulação e circulação dos sentidos.

Campinas: Pontes, 2001.

As formas do silêncio: no movimento dos sentidos. Campinas:

Unicamp, 1993.

Discurso e leitura. Campinas: Unicamp, 1988.

PERUZZOLO, A. C. A circulação do corpo na mídia. Santa Maria: Imprensa Universitária, 1998.

RAMOS, C. M. A. Teorias da tatuagem: corpo tatuado - uma análise da loja Stoppa da Pedra. Florianópolis: Udesc, 2001.

Recebido em 11/09/08. Aprovado em 10/02/09.

Title: Tattoo as a genre: a discursive view

Author: Sandro Braga

Abstract: This article presents a reading perspective of the semiotic material which is constitutive of tattoos as a discursive genre. In order to do so, based on the Bakhtinian theoretical framework on speech genres, an interface is established with the French discourse analysis trend

Keywords: discourse; genre; tattoo.

Titre: Le tatouage comme genre: un regard discursive

Auteur: Sandro Braga

Résumé: Cet article présente une perspective de lecture du matériel sémiotique constitutif du tatouage comme un genre discursif. Ainsi, on part de la charpente théorique bakhtinienne sur les genres du discours, tout en établissant une interface avec l'École Française de l'Analyse du Discours.

Mots-clés: discours; genre discursif; tatouage.

BRAGA - A tatuagem como gênero... 
Título: El tatuaje como género: una mirada discursiva

Autor: Sandro Braga

Resumen: Este artículo presenta una perspectiva de lectura del material semiótico constitutivo del tatuaje como un género discursivo. Para eso, se parte del esbozo teórico bakhtiniano acerca de los géneros del discurso, estableciendo una interfase con el Análisis del Discurso de corriente francesa.

Palabras-clave: discurso; género discursivo; tatuaje. 